\title{
Facile Synthesis of Three Kobolds: Introducing Students to the Structure of Pigments and Their Characterization
}

\author{
Pablo Martín-Ramos, ${ }^{\dagger \neq}{ }^{\ddagger}$ Maria Susano, ${ }^{\dagger}$ Francisco P. S. C. Gil ${ }^{\dagger, \S}$ Pedro S. Pereira da Silva, ${ }^{\dagger}$ \\ Jesús Martín-Gil," and Manuela Ramos Silva* ${ }^{* \dagger \odot}$ \\ ${ }^{\dagger}$ CFisUC, Department of Physics, University of Coimbra, P3004-516 Coimbra, Portugal \\ ${ }^{\ddagger}$ EPS, Instituto de Investigación en Ciencias Ambientales de Aragón (IUCA), Universidad de Zaragoza, Carretera de Cuarte s/n, \\ 22071 Huesca, Spain \\ ${ }^{\S}$ Research Unit Molecular Chemical-Physics, Department of Chemistry, University of Coimbra, P3004-516 Coimbra, Portugal \\ "ETSIIAA, Universidad de Valladolid, Avda. Madrid 44, 34004 Palencia, Spain
}

Supporting Information

ABSTRACT: Thénard's blue $\left(\mathrm{CoAl}_{2} \mathrm{O}_{4}\right)$, Rinman's green $\left(\mathrm{CoZnO}_{2}\right)$, and Berzelius' red $\left(\mathrm{CoMgO}_{2}\right)$ are pigments that have been used from the 19th century in works of art. Their synthesis can be conducted by a very simple and rapid method: by ignition of a wafer of dried filter paper soaked first in a $\mathrm{Co}^{2+}$ solution and then subsequently soaked in a partner salt $\left(\mathrm{Al}^{3+}\right.$, $\mathrm{Zn}^{2+}$, or $\mathrm{Mg}^{2+}$ ) solution. Through their following characterization using X-ray powder diffraction (XRPD) and scanning electron microscopy (SEM), the students can be introduced to further concepts, protocols for sample preparation, and data interpretation regarding these mainstream characterization techniques. Although originally designed for first-year undergraduates, this activity can be tailored to match different levels

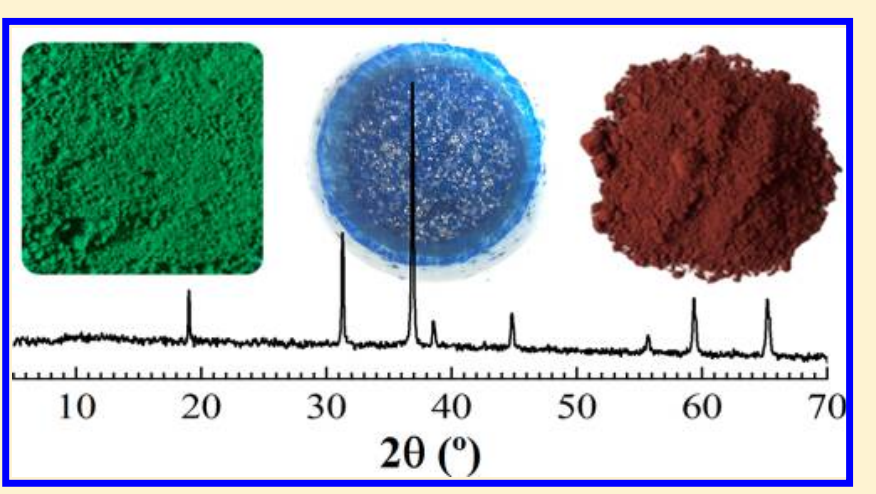
and can be used as a part of STEAM (science, technology, engineering, arts, and mathematics) activities in middle/high school and general public outreach.

KEYWORDS: Elementary/Middle School Science, High School/Introductory Chemistry, First-Year Undergraduate/General, Materials Science, Dyes/Pigments, X-ray Crystallography, Synthesis, Spectroscopy, Hands-On Learning/Manipulatives

$\mathrm{T}$ hroughout history, pigments have been prepared in many different ways, from grinding naturally occurring minerals, such as cinnabar or lapis lazuli, to the serendipitous discovery of Prussian blue $^{1}$ or to current research on environmentally friendly alternatives. Even today, new colors are being added to the palette available to artists and children, just like a new shade of blue resulting from a mixture of yttrium oxide, indium oxide, and a bit of manganese oxide that Crayola has turned into a new crayon. ${ }^{2}$ Some colors can be produced by precipitation of insoluble pigments by interaction of aqueous solutions of soluble salts, like chrome yellow, ${ }^{3}$ while others, such as Verdigris ("green of Greece"), come from the corrosion of copper and can be collected by scraping the colored crust from sheets of copper exposed to vapors (from vinegar, wine). ${ }^{4}$ Other pigments are pyrogenetic in origin; that is, they are formed by calcination of the starting materials in a furnace. Examples are ultramarine blue, chromium oxide green, ${ }^{5}$ or the materials studied herein.

\section{BACKGROUND}

Cobalt pigments that originated from mineral mines in Bohemia were called "kobolds" from the Bohemian word for ghosts or spirits. ${ }^{6}$ The Bohemian miners felt the minerals were haunted by spirits causing them all manner of ailments and difficulties!

Cobalt blue (Figure 1, left) was developed for porcelain in China, ${ }^{7}$ but it was independently discovered as a pure aluminabased pigment by Louis Jacques Thénard in $1802 .{ }^{8}$ Commercial production began in France in 1807, although the leading world manufacturer of cobalt blue in the 19th century was Benjamin Wegner's Norwegian company Blaafarveværket. Thénard's blue was used in Claude Monet's Grenouillere Bathing (1869), in Pierre-Auguste Renoir's Les Parapluies (1881-1885), and in Vincent van Gogh's Starry Night Over the Rhone (1888) paintings, for example. Van Gogh wrote to his brother Theo, "Cobalt [blue] is a divine color and there is nothing so beautiful for putting atmosphere around things...".

When cobalt oxide is ignited with zinc oxide instead of aluminum oxide, a semitransparent, bright green, with a low tinting strength green color is obtained: Rinman's green (cobalt

Received: June 10, 2017

Revised: April 30, 2018

Published: June 29, 2018 


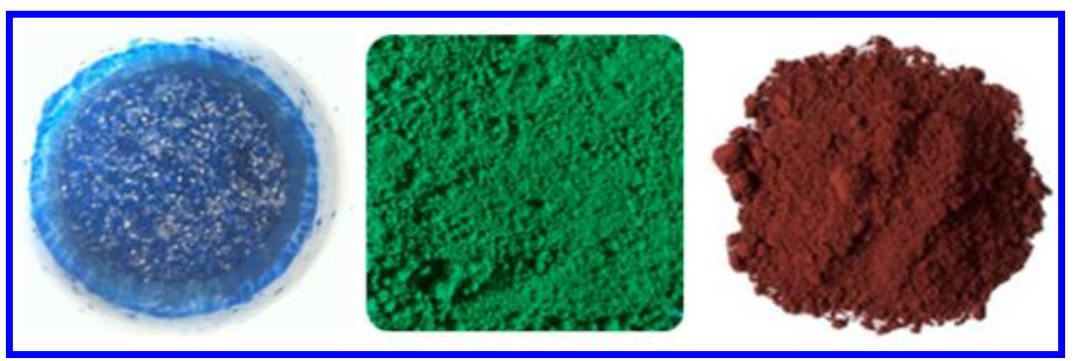

Figure 1. From left to right: Thénard's blue, Rinman's green, and Berzelius' red.

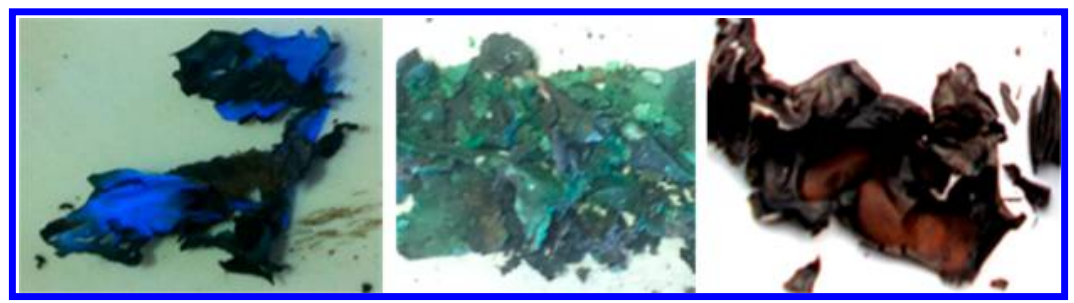

Figure 2. Colored ashes after ignition of the filter paper used as a support for the $\mathrm{Co}^{2+}$ mixed oxides. From left to right: Thénard's blue, Rinman's green, and Berzelius' red.

green, Gellert's green, or turquoise green; see Figure 1, center). Sven Rinman, a Swedish chemist, discovered this compound in 1780 , but this pigment was not widely used until after 1860 when zinc oxide became more readily available. Arthur Church, a chemist and amateur painter, published Rinman's process in his book The Chemistry of Paints and Painting praising cobalt green as "chemically and artistically perfect". ${ }^{10}$ Unfortunately, the pigment was never an artist's favorite, as it has poor tinting and covering strength. However, it has excellent lightfastness, and its transparency makes it ideal for glazing. ${ }^{11}$ Today, cobalt green is a good candidate for testing as a spintronics material: it could be used to form a magnetic thin film in a future nonvolatile memory. ${ }^{12}$

On the other hand, when cobalt oxide is ignited with magnesium oxide, a pretty pale red or pink color is obtained (Figure 1, right): Berzelius' red (Jöns Jacob Berzelius was first to describe this pigment). Depending on the firing conditions (i.e., oxidation or reduction), the mixed oxide could become purple or reddish blue. Pink color is obtained when $\mathrm{Co}^{2+}$ ions are coordinated by six oxygen atoms, but coordination to four oxygen atoms will give rise to the undesired blue color. Consequently, Berzelius' red is not, per se, a useful ceramic pigment.

\section{THE ACTIVITY}

This hands-on activity is suitable for chemistry or materials science first-year students, or for students of heritage conservation and fine arts, ${ }^{13-15}$ and can be carried out in a $90 \mathrm{~min}$ session, but it requires access to a central instrumentation laboratory. The introductory part consists of a general comment (15 min oral session) on the history of the kobolds or $\mathrm{Co}$ (II)-based pigments, their applications, their structures, and the usual methods followed in their preparation (as reported below). The teacher then conducts the experiment, and the students replicate it (20 $\mathrm{min}$, in small groups), after which the teacher begins the second part of the session proposing two methods to identify these pigments in ashes: XRPD $^{16,17}$ and SEM-EDS microscopy. ${ }^{18,19}$ During the remaining $55 \mathrm{~min}$, the teacher explains the basics of these techniques; lab technicians record the XRPD patterns and
SEM-EDS patterns of pigmented ashes in front of the students, and the characterization of the samples is explained by the teacher. Students are finally asked to write a brief report in which, besides commenting on the synthesis and characterization techniques used, they should explain the analysis of the experimental results, using a scientific style. This will allow the instructor to assess the students' understanding of the entire activity and their scientific writing skills.

\section{Materials}

The reagents used in the activity are inexpensive hydrated salts (cobalt(II) nitrate, aluminum nitrate, zinc nitrate, and magnesium nitrate) and filter paper, which can be easily purchased from lab suppliers.

\section{Procedure}

The conventional procedure for the synthesis of $\mathrm{CoAl}_{2} \mathrm{O}_{4}$, $\mathrm{CoZnO}_{2}$, or $\mathrm{CoMgO}_{2}$ is the ceramic method. An oxygen containing cobalt precursor, such as cobalt nitrate or cobalt oxalate, is mixed with alumina, zinc oxide, or magnesium oxide and ground in a ball mill. The mixtures are then calcinated to form the compounds, which become thermally stable above $650{ }^{\circ} \mathrm{C} .{ }^{20}$

However, in the proposed (nonconventional) preparation method, a wafer of filter paper is first soaked in a diluted solution of cobalt nitrate, and then, using tweezers, it is forced to dry by being waved over the flame of a Bunsen burner. When, subsequently, a solution of $\mathrm{Al}^{3+}, \mathrm{Zn}^{2+}$, or $\mathrm{Mg}^{2+}$ salt is added, the paper filter changes its color to blue, green, or red/ pink, respectively. These colors can be enhanced by drying and ignition. Because high quality filters are made of refined pulp and/or pure cotton linters (with an alpha-cellulose content over 95\%), they suffer ignition giving a low ash content, but the resulting ashes have the desired blue, green, or red colors (Figure 2).

\section{Hazards}

The salts used in the experiment are irritants in case of skin contact (prolonged exposure may result in skin burns and ulcerations), of eye contact, of ingestion, and of inhalation. They should be handled by students wearing gloves, goggles, and laboratory coats and working in a well-ventilated area (or 


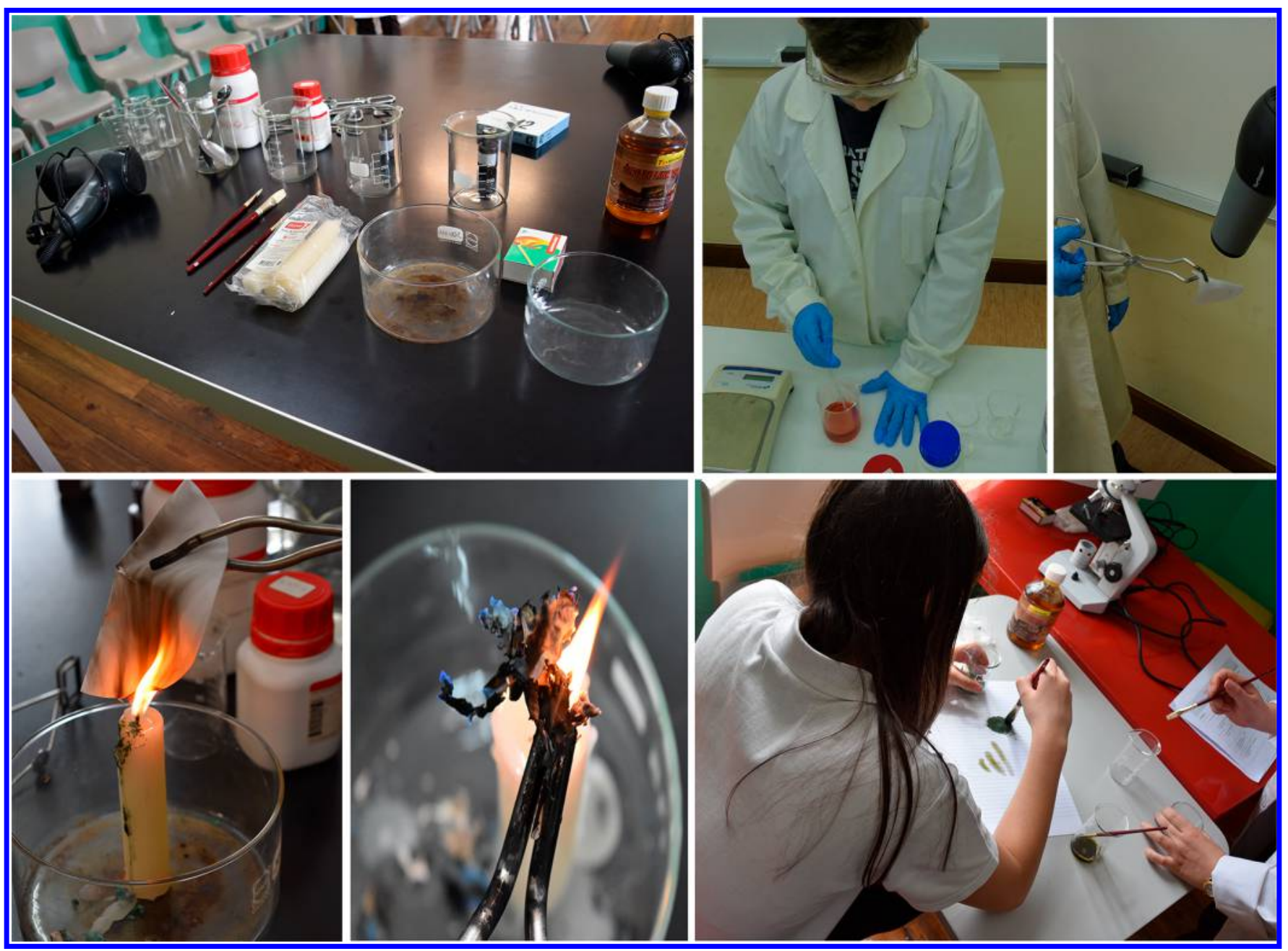

Figure 3. Photos taken during an informal session at a middle school (students aged 12-14). From left to right: materials needed, student preparing one of the solutions, students drying the soaked filter paper with a hair drier, student burning the filter paper using a candle, blue ashes, and student using the just made green pigment mixed with linseed oil.

under a fume hood). Special care should be taken when grinding the pigments. All laboratory activities should be carried out under the supervision of trained and qualified personnel.

\section{Student Learning Objectives}

The key learning objectives of this activity include the following:

(i) Carry out the facile synthesis of cobalt-based pigments;

(ii) Understand how the color of a crystal can be affected by distorting or changing the dimensions of the crystal structure;

(iii) Obtain hands-on experience with two well-known characterization techniques;

(iv) Realize how different characterization techniques can play an important role in museums through pigments identification, an aspect of science to which most students are not exposed.

\section{RESULTS AND DISCUSSION}

The instructor notes in the Supporting Information (SI) provide educational materials (text and images) describing these characterization techniques, procedures for sample preparation, and data analyses. The as-prepared ashes were ground in an agate mortar and used both for XRPD and SEMEDS. The ashes contained enough crystalline material so that well-resolved diffraction peaks could be collected with a fast (15 min) scan in the $2 \theta=5-70^{\circ}$ range. The measured diffractograms are easily matched up with the expected ones for $\mathrm{CoAl}_{2} \mathrm{O}_{4}, \mathrm{CoZnO}_{2}$, and $\mathrm{CoMgO}_{2}$. Micrographs at low magnification were then collected for the (noncoated) samples in the SEM, so that students could observe the porous structure and flaky arrangement of the samples. The EDS analyses, albeit semiquantitative, were consistent with the $\mathrm{X}$-ray powder diffraction data.

This experiment provides students with exposure to two characterization techniques (XRPD and SEM) that they will find in research laboratories and professional contexts, so they will be better prepared for careers or further study in chemistry. They can learn how these techniques can play an important role in museums, an aspect of science to which most students are not exposed, as noted by Rogge and Bezur. ${ }^{21}$

\section{MODIFICATIONS TO THE ACTIVITY}

The beauty of this activity is that it can be easily modified to reach a broad range of students at various levels. It can be implemented in a range of educational settings, including elementary, middle, and high school classrooms through 
outreach and in informal settings. ${ }^{22-24}$ By slightly tuning the proposed synthesis procedure, using a hair dryer and a candle instead of a Bunsen burner to first dry and then ignite the filter paper, students can obtain the pigments in less than 5 min (Figure 3). Grinding the colored ashes and mixing them with linseed oil (or arabic gum or egg yolk ${ }^{25}$ ) readily allows them to paint their own Starry Night as Van Gogh did! The live experiment (initially conducted by the researcher and then by the public) can be accompanied by a general introduction about kobolds from German folklore, colors, and pigments. A suggested complementary activity (shown in Supporting Information) would be to include the use of a hand-held spectrophotometer afterward, with a brief explanation on the importance of the light-scattering power of pigments, including those used in our clothes and skin: white pigment particles will reflect most of the visible spectrum, while black pigments will absorb most of it, and colored pigments interact by a combination of these processes.

At a university level, the pigments can be further investigated by using other characterization techniques that are widely employed in the fields of inorganic chemistry, materials science, and arts, such as FTIR, Raman, UV-vis spectroscopies, thermogravimetric analysis, and differential thermal analysis. For these techniques a fourth sample should be added to the lot, containing just the ashes of a piece of clean filter paper, as a reference sample, so that the features belonging to the pigments can be separated from those of the substrate. It is also worth pointing out that the experiment can also be adapted for application in teaching institutions without SEM-EDS or XRPD instrumentation (providing students with the SEM images and XRPD results supplied in Supporting Information) or for certain combinations of available instrumentation. This makes this experiment very versatile and adaptable to a variety of contexts.

\section{LEARNING OUTCOMES}

The activity was well-received by the students for several reasons: in outreach activities, the younger students were marveled by the appearance of a color after burning the filter paper and were curious about how it happened. Undergraduate students showed their enthusiasm for working with real scientific instrumentation, and most met the learning outcomes for the lab, as seen by the written reports (for instance, in free translation, “...the observed color for a given compound corresponds to the complementary color of the absorbed radiation... that depends on the type of $3 d$ metal, on the type of the ions that surround it and on their spatial arrangement..."). However, perhaps the most rewarding feedback came from art and conservation students, who recognized how different characterization techniques can play an important role in museums through pigments identification (in real life circumstances, that is, with a mixture of compounds and substrates).

From an instructor's standpoint, it was also a satisfactory lab. All chemicals and materials were readily available, and it offered the opportunity to integrate multidisciplinary concepts in a single activity and to discuss pigments from an interdisciplinary point of view: artistically (i.e., origin of the colors and dyes) and considering the science of materials and chemistry.

\section{ASSOCIATED CONTENT}

\section{Supporting Information}

The Supporting Information is available on the ACS Publications website at DOI: 10.1021/acs.jchemed.7b00402.

Instructor notes (PDF, DOCX)

Undergraduate student handout (PDF, DOCX)

Younger student handout (PDF, DOCX)

High resolution XRD images from Figure 4 in instructor notes (PDF)

High resolution SEM image of Berzelius' red from Figure 5 in instructor notes (PDF)

High resolution SEM image of Thénard's blue from Figure 5 in instructor notes (PDF)

High resolution SEM image of Rinman's green from Figure 5 in instructor notes (TIF)

High resolution image of EDS analysis of Berzelius red from Figure 6 of instructor notes (PDF)

High resolution image of EDS analysis of Rinman's green from Figure 6 of instructor notes (PDF)

High resolution image of EDS analysis of Thénard's blue from Figure 6 of instructor notes (PDF)

\section{AUTHOR INFORMATION}

\section{Corresponding Author}

*E-mail: manuela@uc.pt.

ORCID 우

Pablo Martín-Ramos: 0000-0003-2713-2786

Pedro S. Pereira da Silva: 0000-0002-6760-4517

Manuela Ramos Silva: 0000-0001-9555-8856

Notes

The authors declare no competing financial interest.

\section{ACKNOWLEDGMENTS}

Access to TAIL-UC facility funded under QREN-Mais Centro Project ICT 2009020121890 is gratefully acknowledged. This work was supported by FCT through project UID/FIS/ 04564/2016. M.S. thanks FCT for providing her grant under the doctoral programme ChemMat. P.M.-R would like to thank Santander Universidades for its financial support through the "Becas Iberoamérica Jóvenes Profesores e Investigadores, España” scholarship program.

\section{REFERENCES}

(1) Ware, M. Prussian Blue: Artists' Pigment and Chemists' Sponge. L. Chem. Educ. 2008, 85 (5), 612.

(2) Knapton, S. First new shade of blue discovered for 200 years to be turned into Crayola crayon. http://www.telegraph.co.uk/science/ 2017/05/12/first-new-shade-blue-discovered-200-years-turnedcrayola-crayon/ (accessed Apr 2018).

(3) Gaquere-Parker, A. C.; Hill, P. S.; Haaf, M. P.; Parker, C. D.; Doles, N. A.; Yi, A. K.; Kaminski, T. A. Pigment Synthesis for the Exploration of Binding Media Using a Lead-Free Alternative to Chrome Yellow. I. Chem. Educ. 2017, 94 (2), 235-239.

(4) Solomon, S. D.; Rutkowsky, S. A.; Mahon, M. L.; Halpern, E. M. Synthesis of Copper Pigments, Malachite and Verdigris: Making

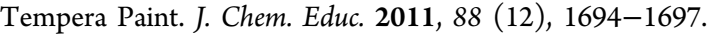

(5) Orna, M. V. Chemistry and artists' colors. Part III. Preparation

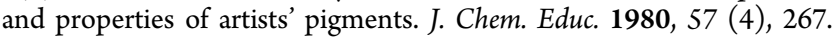

(6) Krebs, R. E. The History and Use of Our Earth's Chemical Elements: A Reference Guide, 2nd ed.; Greenwood Press: Westport, CT, 2006; p $422+\mathrm{xxv}$. 
(7) Kerr, R.; Needham, J.; Wood, N. Science and Civilisation in China: Chemistry and Chemical Technology. Ceramic Technology; Cambridge University Press: Cambridge, U.K., 2004; Vol. 5, Part 12, p 968.

(8) Thénard, L. J. Considérations générales sur les couleurs, suivies d'un procédé pour préparer une couleur bleue aussi belle que l'outremer. Journal des Mines 1803, 86, 128-136.

(9) van Gogh, V.; Roskill, M. W. The Letters of Vincent van Gogh, Touchstone trade pbk ed.; Touchstone: New York, 2008, p 351.

(10) Church, A. H. The Chemistry of Paints and Painting, 4th ed.; Seeley, Service \& Co., Limited: London, 1915; 388 p.

(11) Douma, M. Pigments through the Ages. http://www. webexhibits.org/pigments (accessed Apr 2018).

(12) Djerdj, I.; Jagličić, Z.; Arčon, D.; Niederberger, M. Co-Doped $\mathrm{ZnO}$ nanoparticles: Minireview. Nanoscale 2010, 2 (7), 1096-1104.

(13) Hemraj-Benny, T.; Beckford, I. Cooperative and Inquiry-Based Learning Utilizing Art-Related Topics: Teaching Chemistry to Community College Nonscience Majors. L. Chem. Educ. 2014, 91 (10), 1618-1622.

(14) Nivens, D. A.; Padgett, C. W.; Chase, J. M.; Verges, K. J.; Jamieson, D. S. Art, Meet Chemistry; Chemistry, Meet Art: Case Studies, Current Literature, and Instrumental Methods Combined To Create a Hands-On Experience for Nonmajors and Instrumental Analysis Students. J. Chem. Educ. 2010, 87 (10), 1089-1093.

(15) Wells, G.; Haaf, M. Investigating Art Objects through Collaborative Student Research Projects in an Undergraduate Chemistry and Art Course. I. Chem. Educ. 2013, 90 (12), 1616-1621.

(16) Leyral, G.; Bernaud, L.; Manteghetti, A.; Filhol, J.-S. Microwave Synthesis of a Fluorescent Ruby Powder. I. Chem. Educ. 2013, 90 (10), $1380-1383$.

(17) Varberg, T. D.; Skakuj, K. X-ray Diffraction of Intermetallic Compounds: A Physical Chemistry Laboratory Experiment. I. Chem. Educ. 2015, 92 (6), 1095-1097.

(18) Uffelman, E. S. Teaching Science in Art. I. Chem. Educ. 2007, 84 (10), 1617.

(19) Hill, A. D.; Lehman, A. H.; Parr, M. L. Using Scanning Electron Microscopy with Energy Dispersive X-ray Spectroscopy To Analyze Archaeological Materials. Introducing Scientific Concepts and Scientific Literacy to Students from All Disciplines. I. Chem. Educ. 2007, 84 (5), 810.

(20) Melo, D. M. A.; Cunha, J. D.; Fernandes, J. D. G.; Bernardi, M. I.; Melo, M. A. F.; Martinelli, A. E. Evaluation of $\mathrm{CoAl} 2 \mathrm{O} 4$ as ceramic pigments. Mater. Res. Bull. 2003, 38 (9-10), 1559-1564.

(21) Rogge, C. E.; Bezur, A. An Investigation into the Creation, Stability, and X-ray Fluorescence Analysis of Early Photographic Processes: An Upper-Level Undergraduate Laboratory. I. Chem. Educ. 2012, 89 (3), 397-400.

(22) Blatti, J. L. Colorful and Creative Chemistry: Making Simple Sustainable Paints with Natural Pigments and Binders. I. Chem. Educ. 2017, 94 (2), 211-215.

(23) Gettys, N. S. Pigments of Your Imagination: Making Artist's Paints. I. Chem. Educ. 2001, 78 (10), 1320A.

(24) Bopegedera, A. M. R. P. Tie-Dye! An Engaging Activity To Introduce Polymers and Polymerization to Beginning Chemistry Students. I. Chem. Educ. 2017, 94 (11), 1725-1732.

(25) Gaquere-Parker, A. C.; Doles, N. A.; Parker, C. D. Chemistry and Art in a Bag: An Easy-To-Implement Outreach Activity Making and Painting with a Copper-Based Pigment. I. Chem. Educ. 2016, 93 (1), 152-153. 